\title{
Most Drug Overdose Deaths from Nonprescription Opioids
}

The Centers for Disease Control (CDC) is reporting in Morbidity and Mortality Weekly that the number of people dying from an opioid overdose rose $15.5 \%$ from 2014 to 2015, but the increase had little to do with prescription painkillers such as oxycodone or hydrocodone (1). Roughly 52,000 people died from drug overdoses in 2015 and of those deaths 33,091 involved an opioid. The increases in "death rates were driven by synthetic opioids other than methadone $(72.2 \%)$, most likely illicitly-manufactured fentanyl, and heroin (20.6\%)". Deaths from methadone, which is usually prescribed by physicians, decreased $9.1 \%$.

The largest increase in deaths occurred in the South and Northeast with $3 \%$ and $24 \%$ increases in deaths from synthetic opioids from 2014 to 2015 . In the Midwest and West, there were more modest $17 \%$ and $9 \%$ increases during the same period. States in the Southwest with "good" to "excellent" reporting included Colorado, Nevada, and New Mexico which showed 33\%, 14\% and 30\% decreases respectively.

Earlier this year, CDC Director Tom Frieden, MD, MPH, said "The prescription overdose epidemic is doctor-driven... It can be reversed in part by doctors' actions" (2). That characterization has rung in some physicians' ears as blame for the entire opioid crisis, including deaths from heroin and illegal fentanyl. The data in the present article suggests that characterization is inaccurate and that efforts by a number of State Boards to limit physician opioid prescribing may be marginally or non-effective in reducing overdose deaths.

Richard A. Robbins, MD

Editor, SWJPCC

\section{References}

1. Rudd RA, Seth P, David F, Scholl L. Increases in drug and opioid-involved overdose deaths - United States, 2010-2015. MMWR Morb Mortal Wkly Rep. 2016 Dec 16;65. Published on-line. [CrossRef]

2. Lowes R. CDC issues opioid guidelines for 'doctor-driven' epidemic. Medscape. March 15, 2016. Available at:

http://www.medscape.com/viewarticle/860452 (accessed 12/21/16). 